\title{
Identification of imperial cormorant Phalacrocorax atriceps behaviour using accelerometers
}

\author{
Agustina Gómez Laich ${ }^{1, *}$, Rory P. Wilson ${ }^{2}$, Flavio Quintana ${ }^{1,3}$, Emily L. C. Shepard ${ }^{2}$ \\ ${ }^{1}$ Centro Nacional Patagónico (CENPAT)-CONICET, (9120) Puerto Madryn, Chubut, Argentina \\ ${ }^{2}$ Biological Sciences, Institute of Environmental Sustainability, University of Wales, Swansea SA2 8PP, UK \\ ${ }^{3}$ Wildlife Conservation Society, 2300 Southern Boulevard, Bronx, New York 10460, USA
}

\begin{abstract}
Animal behaviour is largely defined in terms of movement or lack of it, so precise quantification of animal movement is a potentially powerful way of identifying several animal behaviours. Animal-attached tags that record acceleration lend themselves particularly to this. In this work we show how tri-axial acceleration can be used to identify some of the behaviours of imperial cormorants Phalacrocorax atriceps. Based on the assessment of tri-axial acceleration signals, the following behaviours were identified in free-living birds: standing, sitting, floating on water, flying, walking and diving. During diving, the descent, bottom and ascent phases could be distinguished. We considered the factors which coded for the different behaviours and this allowed us to design a key that will allow researchers assessing tri-axial accelerometry data to identify some of the behaviours that imperial cormorants perform.
\end{abstract}

KEY WORDS: Phalacrocorax atriceps - Imperial cormorant - Acceleration datalogger - Remote monitoring $\cdot$ Behaviour

Resale or republication not permitted without written consent of the publisher

\section{INTRODUCTION}

Over recent years, the development of new technology and the miniaturization of electronic components have allowed researchers to construct recording tags that can be attached to wild animals so as to study the behaviour of species that are difficult to observe (Ropert-Coudert \& Wilson 2005). Data loggers with biaxial acceleration sensors have been deployed on aquatic and terrestrial animal species, and various behaviours have been identified based on particularities in the signals (Yoda et al. 1999, 2001, RopertCoudert et al. 2004, Watanabe et al. 2005).

Although bi-axial accelerometers have proved to be very useful in the differentiation of behaviours, movement usually occurs in all of the 3-dimensional axes so that, theoretically at least, quantification of movement, and thus behaviour, should be more powerful if triaxial accelerometers are used. Despite this, relatively few researchers have used tri-axial accelerometers for the study of animal behaviour, the exceptions being Johnson \& Tyack (2003), and Wilson et al. $(2006,2008)$.
In addition to their use in the study of animal behaviour, accelerometers have also been suggested as useful for alluding to energy expenditure. Studies on great cormorants Phalacrocorax carbo (Wilson et al. 2006) and on humans (Halsey et al. 2008) have shown high correlation coefficients between overall dynamic body acceleration (ODBA) and the rate of oxygen consumption $\left(V \mathrm{O}_{2}\right)$. Clearly, if tri-axial accelerometers can be used to define both energy expenditure and behaviour, then activity-specific energy expenditure can be determined in free-living animals, providing a particularly powerful tool for ecologists. This is also potentially valuable to conservationists, for instance in defining the energetic costs associated with anthropogenically mediated changes in behaviour, such as those following habitat loss or fragmentation (e.g. McLellan \& Shackelton 1988), exposure to human presence as seen in ecotourism (e.g. Bejder et al. 2006), or global change (e.g. Cotton 2003). The ability to record and identify behavioural patterns may also be important where such behaviours may increase the risk of mortality, such as the predation of livestock by 
wild predators, or limit population recovery, e.g. the ability of reintroduced animals to develop the necessary range of behaviours seen in their wild counterparts (Wallace 1994).

In the present study we deployed tri-axial accelerometers on free-living imperial cormorants Phalacrocorax atriceps and analyzed the resultant data to determine the extent to which tri-axial acceleration could code for behaviour. A specific objective of this work was to present a systematic key that may serve as a template for other researchers working with seabirds and accelerometers, but also one that would be particularly valuable for people working with cormorants.

\section{MATERIALS AND METHODS}

Field work was conducted in December 2006 at Punta León colony $\left(43^{\circ} 04^{\prime} \mathrm{S}, 64^{\circ} 2^{\prime} \mathrm{W}\right)$, Chubut, Argentina. Fourteen imperial cormorants Phalacrocorax atriceps were equipped with 13 channel dataloggers (largest dimensions $65 \times 36 \times 22 \mathrm{~mm}$, mass $40 \mathrm{~g}$ ) recording data with a resolution of 22 bits into a $512 \mathrm{Mb}$ memory. Ten of the devices recorded data at $8 \mathrm{~Hz}$, while the remaining 4 recorded data at $9 \mathrm{~Hz}$. Although this study aspired to deal only with acceleration data, the other sensors measuring speed, light, triaxial magnetometry, pressure, pitch and roll (these latter 2 being derived from surge and sway acceleration; for details see Wilson et al. 2008) were used to help verify particular behaviours at times when birds could not be observed directly (such as when they were foraging at sea). The 3 axes for the acceleration transducers (all perpendicular to each other) were calibrated by rotating the units through all combinations of pitch and roll (0 to $360^{\circ}$ for both rotations) so that output from the transducers could be converted into $g$, where $g$ represents acceleration due to gravity.

All the cormorants fitted with devices were brooding small chicks. A specially designed hook was used to remove the cormorants from the nest. The loggers were attached to the lower back of the animals using TESA tape (Beiersdorf) (Wilson et al. 1997), and great effort was taken to keep the position of the logger identical for all individuals. The procedure was completed in less than 5 min and birds were quickly returned to the nest. The birds were allowed to forage for a single trip before the devices were retrieved.

Downloaded acceleration and body angle data were analyzed using custom-made software. The pitch angle signal was smoothed using a running mean over $2 \mathrm{~s}$ (cf. Shepard et al. 2008, this Theme Section). This measured pitch angle was corrected for imperfect device orientation on the birds' bodies by examining the pitch value from each individual as it rested on the sea sur- face, assuming that this value was representative of the true zero, and correcting all other measured values to accord (cf. Sato et al. 2003, Watanuki et al. 2003).

The 3 acceleration signals (surge, heave and sway), and their transformation into pitch and roll, over time were visually inspected in graph form in order to identify any obvious patterns that might be characteristic of particular behaviours. A brief description of how pitch, heave, sway and surge relate to the cormorant movement is shown in Fig. 1. Stretches of data corresponding to defined behaviours were then assessed for mean values and variance in pitch angle as well as for repetitive patterns in surge, heave and sway signals. In the latter case, the period of the pattern was established.

\section{RESULTS}

Based on the assessment of tri-axial acceleration, the following behaviours could be identified: standing, sitting, floating, flying, walking and diving. For periods when the cormorants were on land there was a clear basic bimodal frequency distribution in pitch (Fig. 2a) although one individual had a small third mode around pitch angles of zero (Fig. 2b). Overall though, the distribution of the pitch angle frequency of all birds pooled together was bimodal (Fig. 2c). The lower mode (around $25^{\circ}$ ) represented periods in which the birds were sitting, while the higher mode (around $65^{\circ}$ ) corresponded to periods in which the birds were standing. The threshold value above which a cormorant was considered to be standing was $46.25^{\circ}$.

Both standing and sitting periods were characterized by steady heave and sway acceleration values with little variance (Table 1, Fig. 3). Floating behaviour could be distinguished from sitting on land by the lower pitch angle values and higher variation in the sway and heave acceleration profiles of the former (Table 1, Figs. 3 \& 4b,c).

Flight was characterized by low pitch angle values (mean $=5^{\circ}$ ) and a clear periodic pattern with a mean frequency of $2.52 \mathrm{~Hz}$ in the heave acceleration trace (Table 1, Fig. 5a). It was during this behaviour that the

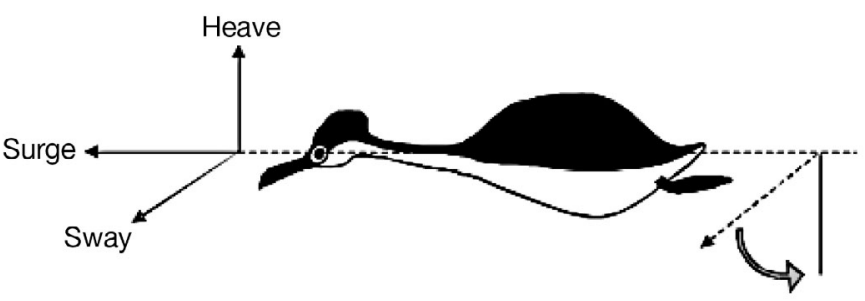

Fig. 1. Phalacrocorax atriceps. Diagram showing how the surge, sway and heave acceleration measurements (solid lines) relate to the cormorant's movements and how the pitch values (grey arrow) relate to the bird's body angle 
greatest variation in the heave acceleration was observed (Table 1, Fig. 3). The difference between landing on land or landing at sea was apparent via the body pitch angle following cessation of flight behaviour (Fig. 6).
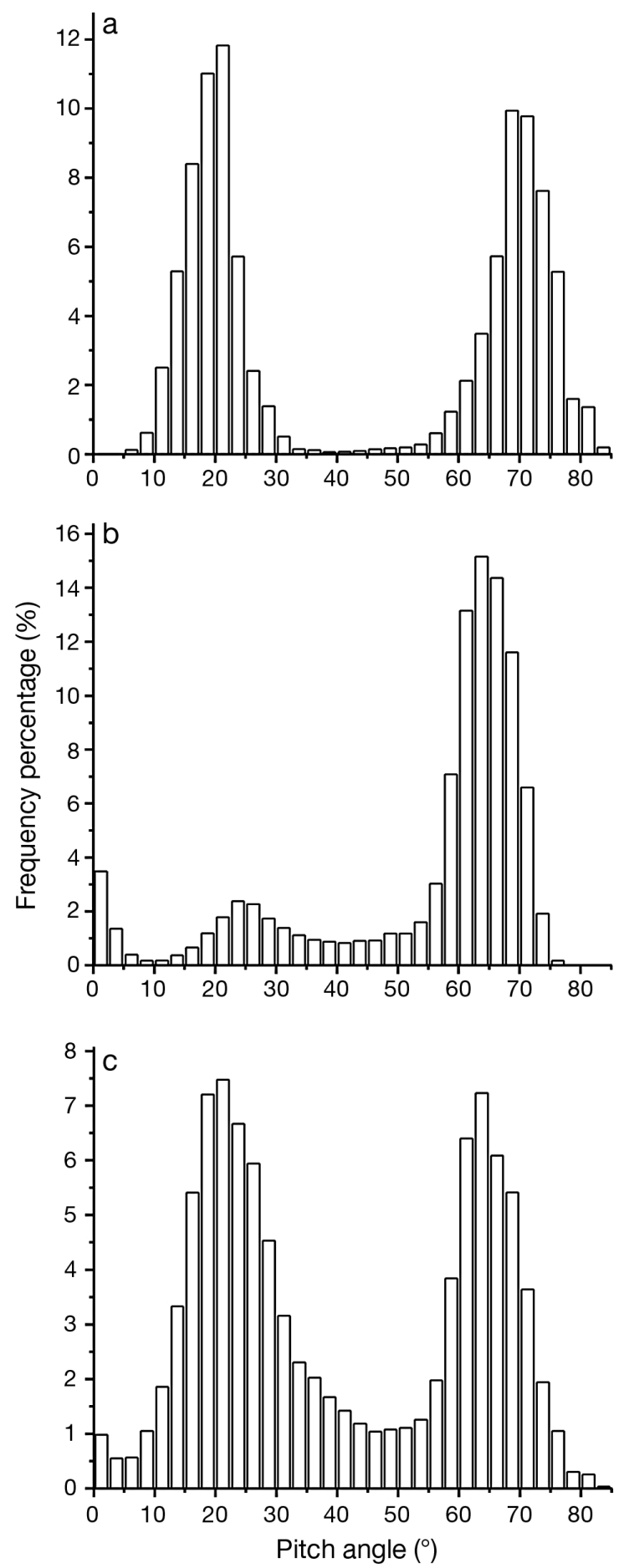

Fig. 2. Phalacrocorax atriceps. Frequency percentage of body pitch for $(a, b) 2$ instrumented females while on land and of (c) 5 (pooled) instrumented cormorants
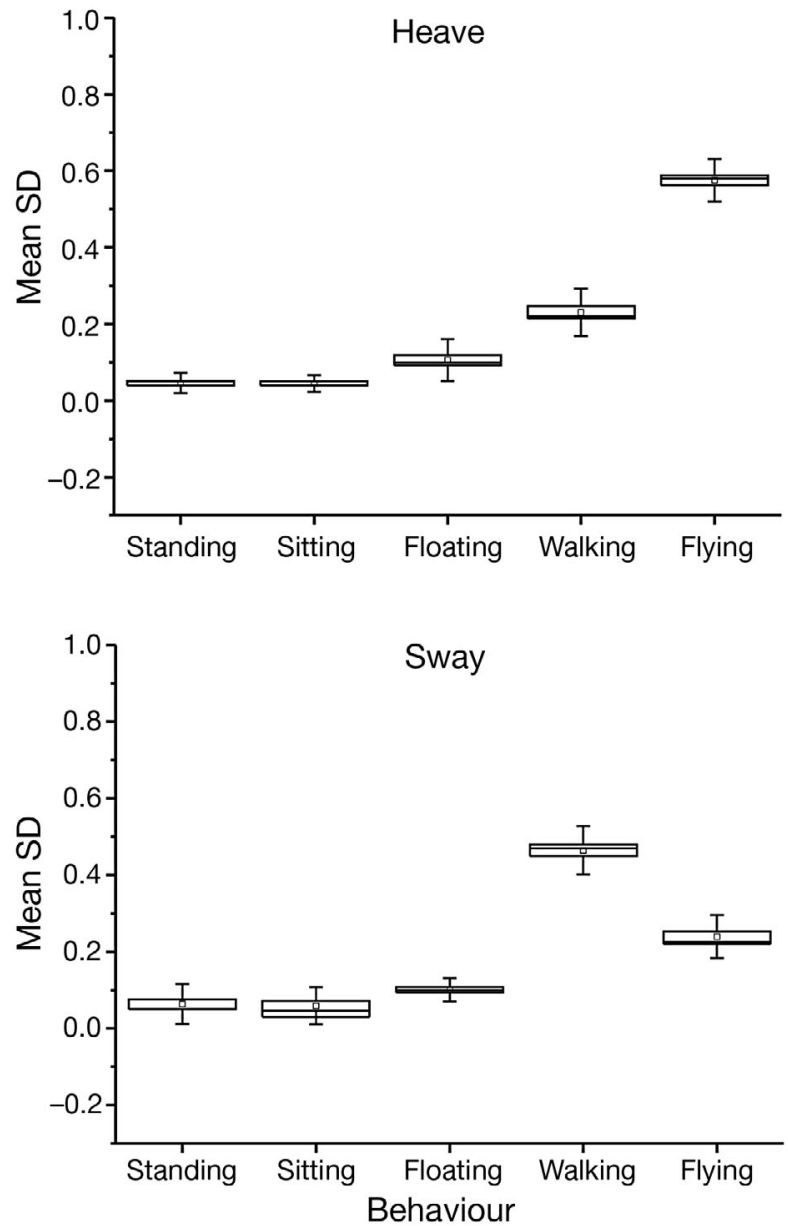

Fig. 3. Phalacrocorax atriceps. Means (rectangles), standard errors (box range), mode (horizontal line) and standard deviations (whiskers) of heave and sway values for 5 of the behaviours recognized for imperial cormorants

Walking showed the highest variation in the sway acceleration trace (Fig. 3) and was characterized by a clear cyclic pattern in sway acceleration with a mean frequency of $1.54 \mathrm{~Hz}$ (Table 1, Fig. 5b).

Diving behaviour could be clearly divided into 3 phases: the descent phase, the bottom phase and the ascent phase. The beginning of a dive was distinguished by a clear peak in the surge acceleration profile. Dive descent phases were characterized by negative pitch angles $\left(\right.$ mean $=-65^{\circ}$ ) accompanied by clear peaks in the heave acceleration (Table 1, Fig. 7a). Ascent phases were characterized by their positive pitch angle values $\left(\right.$ mean $=64^{\circ}$ ) and were always preceded by the characteristic negative pitch angle period of a descent during the preceding $2 \mathrm{~min}$ (Table 1, Fig. $7 \mathrm{c}$ ). Bottom phases were identified by their negative pitch angles $\left(\right.$ mean $=-21^{\circ}$ ) and greater variance in sway acceleration than during descent or ascent (Table 1, Fig. 7b) as well as by the fact that these 


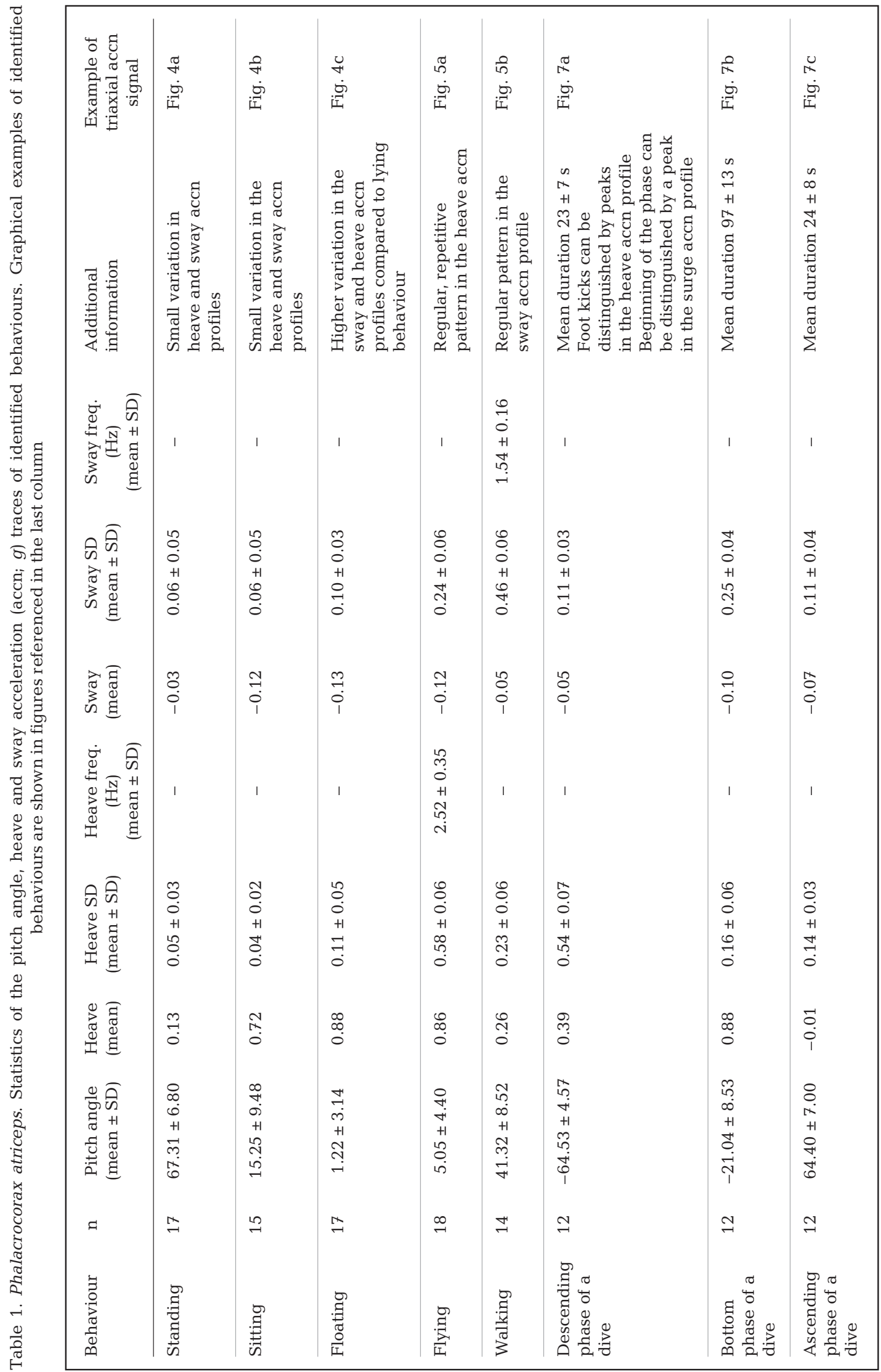



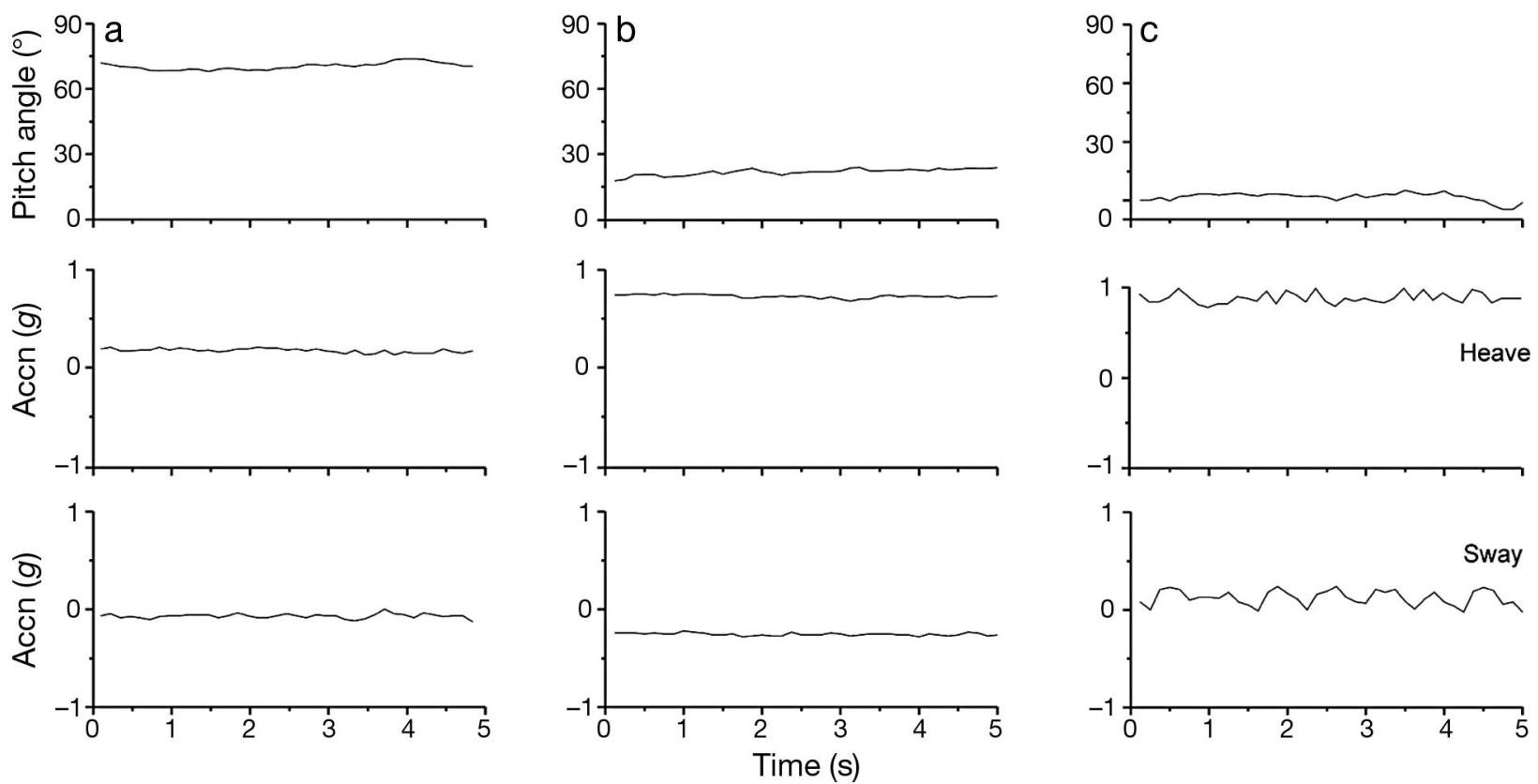

Fig. 4. Phalacrocorax atriceps. Example of the pitch angle and heave and sway acceleration (accn) signals during a period while the bird was (a) standing, (b) sitting or (c) floating on the water surface
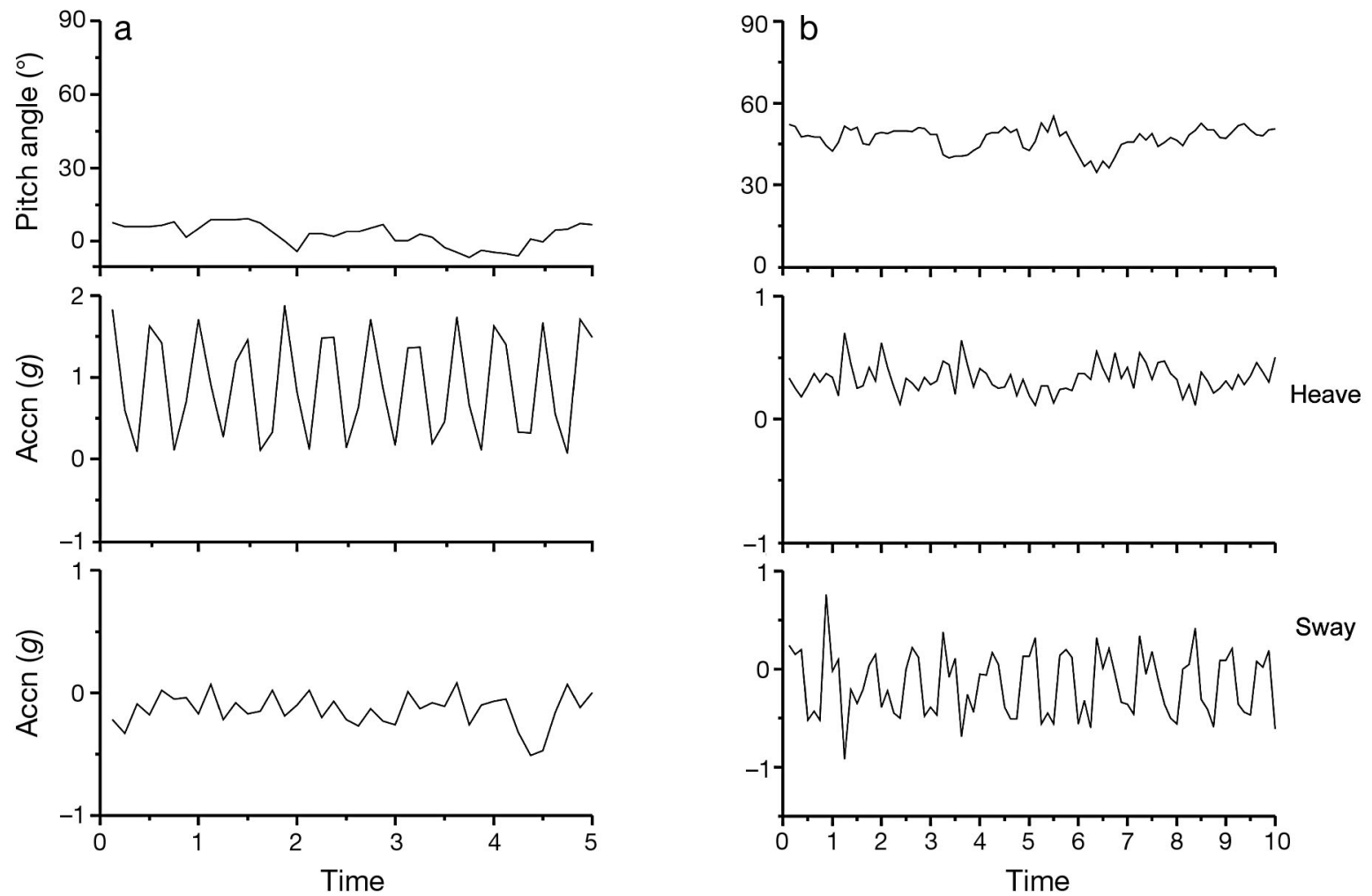

Fig. 5. Phalacrocorax atriceps. Example of the pitch angle and heave and sway acceleration (accn) signals during a period while an imperial cormorant was (a) flying or (b) walking 

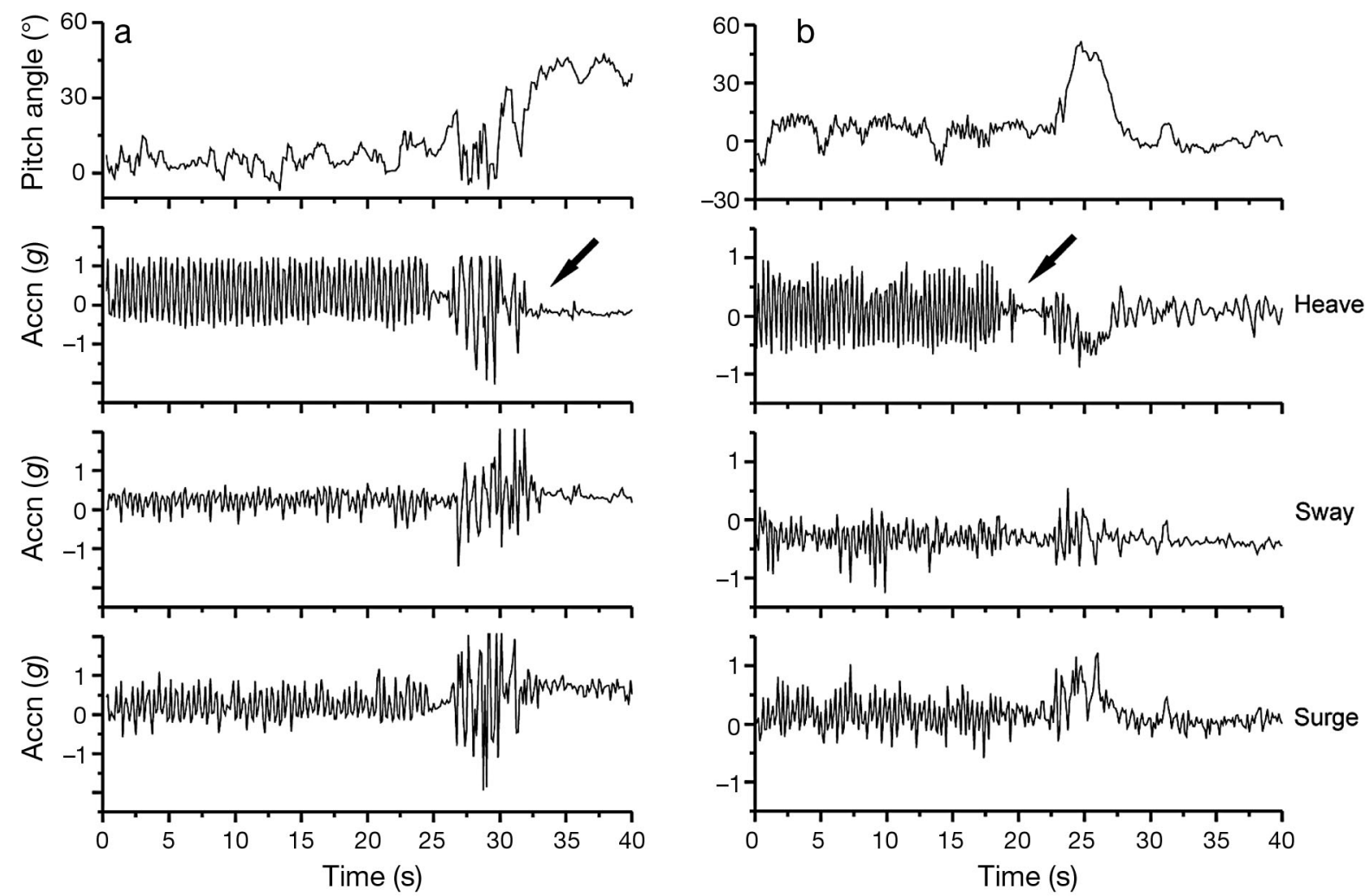

Fig. 6. Phalacrocorax atriceps. Pitch angle and acceleration (accn) profiles during landing (arrow) (a) on land or (b) at sea
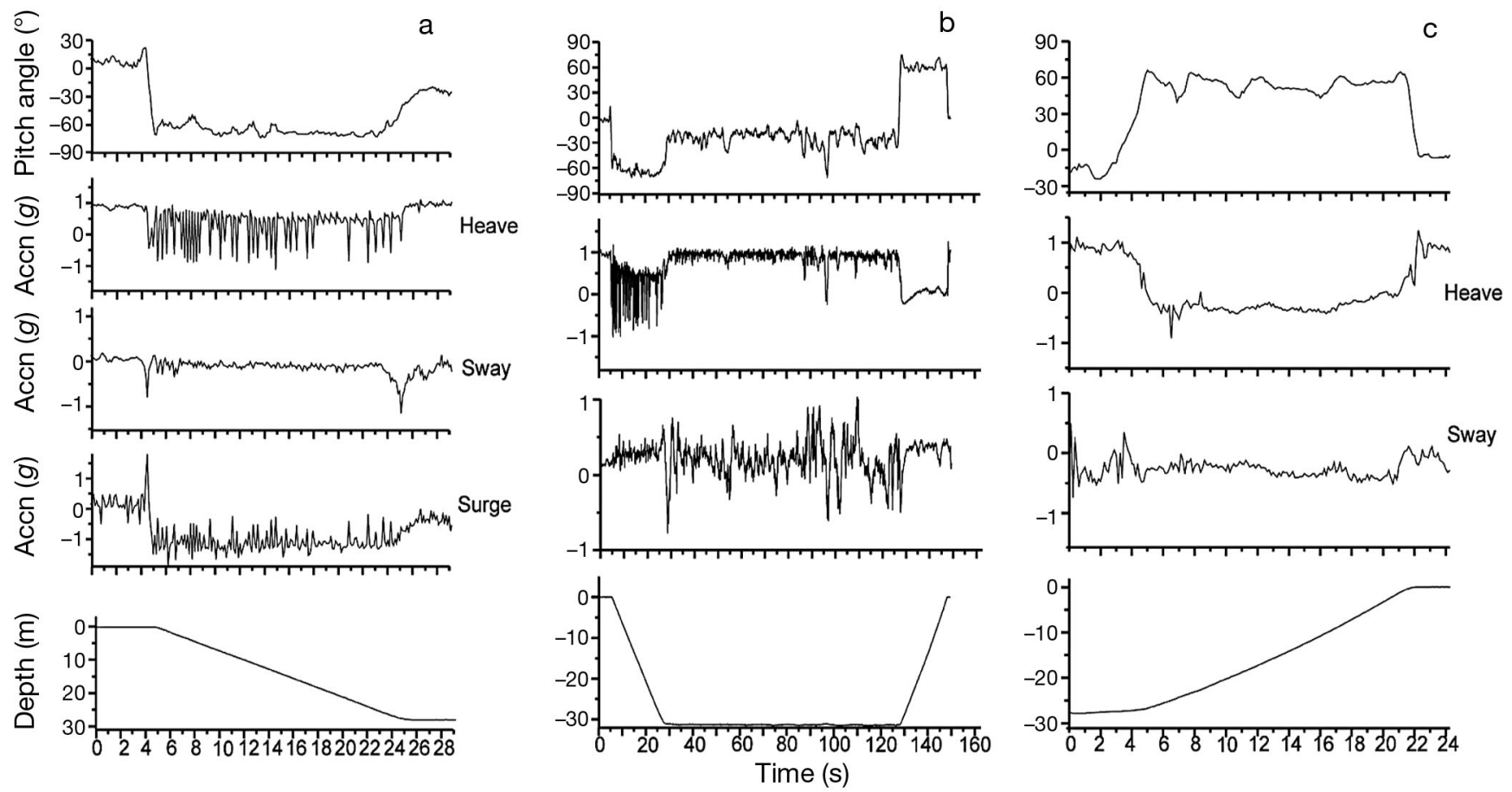

Fig. 7. Phalacrocorax atriceps. Example of the pitch angle and acceleration (accn) signals during the (a) descent phase, (b) bottom phase or (c) ascent phase of a dive. Depth information is presented to aid comprehension 
phases were preceded by a descent phase and followed by an ascent phase.

If we consider all the factors which code for the different behaviours, this allows us to present a schematic flow-diagram which acts as a key to help differentiate behaviours displayed by imperial cormorants (Fig. 8).

\section{DISCUSSION}

This work demonstrates that the use of tri-axial accelerometers attached to free-living animals has great potential for quick and easy identification of behaviours. Even though animal movements may be studied by the means of others systems (e.g. GPS technology; Gremillet et al. 2004, Ryan et al. 2004, Weimerskirch et al. 2005) and some aspects of activity can be determined by using specific transducers (e.g. time depth recorders; Tremblay et al. 2003), tri-axial accelerometers permit an accurate quantification of any movement (even that which does not result in translocation) and thus have great potential for studies of behaviour, irrespective of animal locality (Shepard et al. 2008, Wilson et al. 2008). In addition, since measures of dynamic acceleration correlate with energy expenditure (Wilson et al. 2006, Halsey et al. 2008), accelerometry data can be used to determine how free-living animals partition their energy into particular behaviours.

A number of authors have already noted the value of acceleration in describing the behaviour of birds and mammals (e.g. Davis et al. 1999, Yoda et al. 1999, 2001, Arai et al. 2000, Ropert-Coudert et al. 2004, Watanabe et al. 2005, Wilson et al. 2006, 2008, Shepard et al. 2008), but few have been systematic and specific for a suite of behaviours (but see Yoda et al. 1999, 2001,

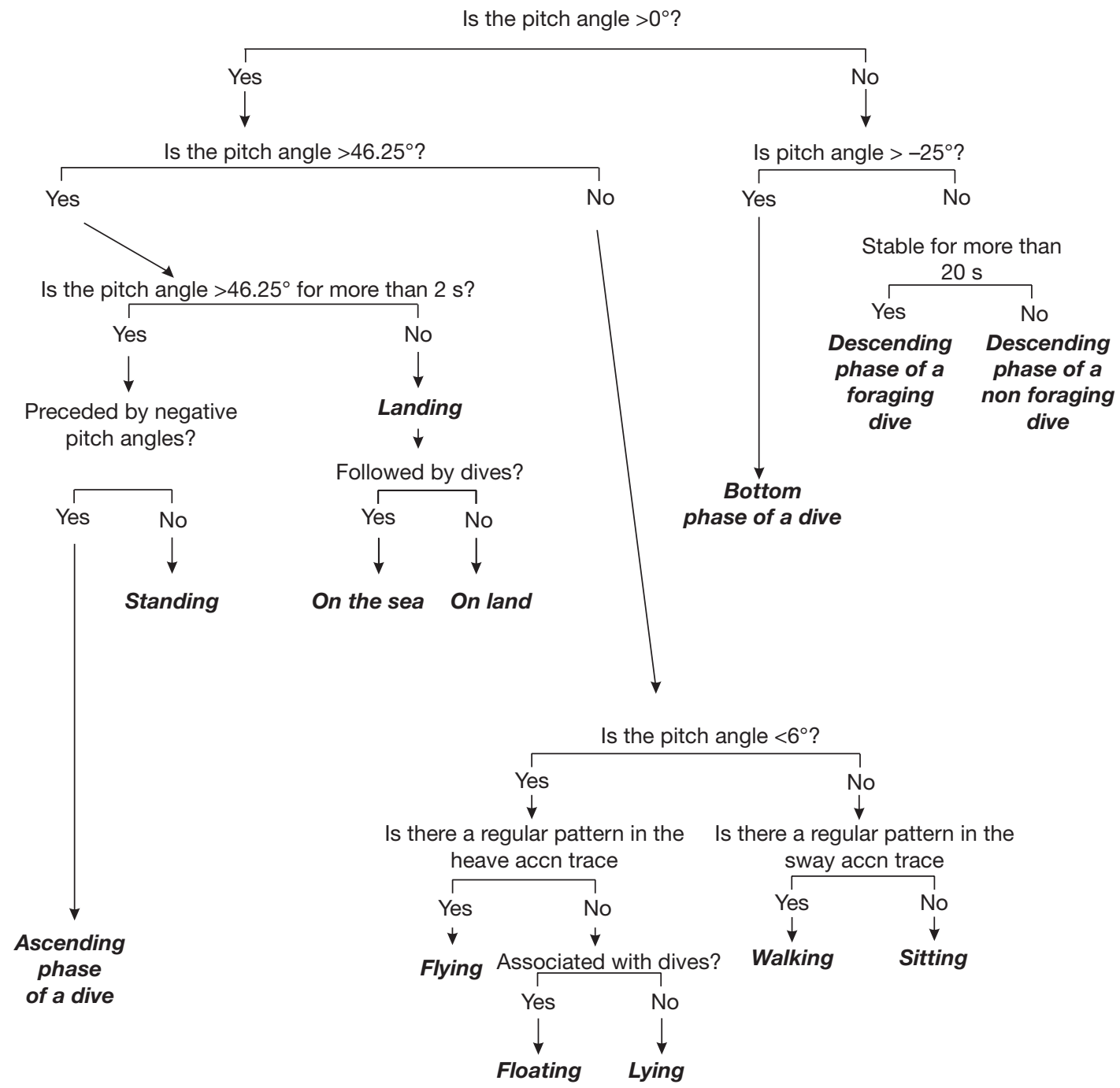

Fig. 8. Phalacrocorax atriceps. Diagram acting as a key to showing how pitch angle and tri-axial acceleration (accn) can be used to identify imperial cormorant behaviours 
Watanabe et al. 2005, Shepard et al. 2008) and most relate to aquatic organisms (with the notable exceptions of Watanabe et al. 2005 and Shepard et al. 2008). Watanabe et al. (2005) presented a complex analysis of how to differentiate behaviours exhibited by a domestic cat Felis catus using a mono-axial acceleration transducer and using spectral analysis based on a Fast Fourier Transform. While powerful, this approach is not readily accessible due to its complexity and may be simply because the acceleration data were collected for only 1 axis and movement frequently occurs in all of the 3-dimensional axes. We would argue that for most researchers the approach used by Yoda et al. (1999), involving simple consideration of body pitch and roll in combination with variance in acceleration axes and identification of repetitive patterns, is more intuitive and more easily carried out. We note here, though, that our approach relates to very major behavioural categories and that the signals coding for these behaviours are expected to be the most obvious. Other behaviours, particularly those that are transitory and/or highly variable, such as preening, chick-feeding and threatening conspecifics, among others, are undoubtedly more problematic and may be best dealt with by techniques such as the spectral analysis following Fast Fourier transformation advocated by Watanabe et al. (2005).

Whatever system is used for identification, there needs to be maximum provision for unique coding signals and clear cutoff points where one behaviour leads into another. For example, during periods when the studied imperial cormorants were on land, and almost no variation was observed in the heave and sway acceleration, the pitch angle information was used to determine if the birds were lying, sitting or standing. It is germane that, although the frequency distributions show clear modes (Fig. 1), the spreads around the modes overlap. This is due, in part, to birds lying on the beach, head up, or head down, on an incline, and in part to slow, and/or multiple transitions between lying and standing. Inter-individual differences observed in pitch frequency distributions (cf. Fig. 2a,b) could, therefore, represent terrain differences encountered by the birds, individual lying preferences or differences in the way individuals move between behaviours.

Although floating on the sea surface and lying on land behaviours had similar pitch angle values, the higher variation in the sway and heave acceleration profiles of the former permitted successful identification of both behaviours. Distinguishing between floating and lying periods might be more problematic if the water is particularly calm (many cormorant species forage on inland waterways; De Nie 1995, Bearhop et al. 1999, Carss \& Ekins 2002). A higher variation during floating periods has also been observed on instrumented Adélie penguins Pygoscelis adelia) and has been attributed to sea waves (Yoda et al. 2001). In this regard it would be interesting to determine whether periodicity in acceleration values during floating on the sea surface (Fig. 4b) would code for the periodicity of the waves encountered by the birds.

Flying and walking behaviours were easily distinguished by the periodic pattern they presented in the heave and sway profiles, respectively. These patterns were expected since the downward stroke during wing-beating causes the body to experience an upward force, the reverse being the case during the upward stroke, which would produce an increase in measured heave acceleration during the downstroke and a decrease during the upstroke. When walking, cormorants waddle; thus, the sway acceleration is expected to vary systematically with the steps, with a single waveform representing a step forward by one foot followed by the other.

The beginning of a dive was easily recognized by a clear peak in the surge acceleration profile which represents the pre-dive leap. Simple examination of the highly negative pitch angle enabled us to identify the dive descent phase, although this was also accompanied by a characteristic pattern in both heave and surge. Patterns characteristic of the bottom and then ascent phases followed on as a logical consequence of the descent, although both phases had their own obvious and unique patterns in the acceleration. Thus, although diving behaviour of air-breathing animals is today examined primarily using pressure-transducer technology (Ropert-Coudert \& Wilson 2005), measurement of acceleration is perfectly adequate for workers to be able to record dive descent, bottom and ascent durations and also gives a good measure of the extent to which animals are working in the various phases (Watanuki et al. 2003, 2005). Moreover, acceleration traces could be a promising way of determining feeding events. Previous works have shown that small variations in the depth profile during the bottom phase of a dive are a good indicator of prey capture (Simeone \& Wilson 2003). If a correlation exists between these periods of undulations in the depth profile and certain acceleration traces, the latter could then be used as an indication of feeding events.

We conclude that the measurement of acceleration, and specifically tri-axial acceleration, via miniature archival tags on animals, has great potential for elucidating and quantifying behaviour. Assessment of major behaviours can generally be undertaken visually without having to resort to complex analytical procedures. The simple production of a key, of the type presented here, would likely suffice for procedures put in place by one group to be readily adopted by another 
working on the same, or similar, species. Given the difficulties of studying so many animals that cannot easily be observed, the development and implementation of accelerometers on wild animals in the future heralds an exciting period during which we can expect to make huge advances in understanding how animals modulate their behaviour. Ultimately, the ability to identify and quantify a range of behaviours may provide insight into issues ranging from the fundamental such as reproductive biology - to the fine scale, including the efficiency of individual foraging trips. In this way, these types of data may be applied to conservation issues including the assessment of a species conservation status and the likely effectiveness of management solutions.

Acknowledgements. Research was supported by a Rolex Award for Enterprise awarded to R.P.W. and by the Wildlife Conservation Society. We thank the Organismo Provincial de Turismo for the permits to work in Punta León and the Centro Nacional Patagónico (CONICET) for institutional support. A.G.L. is supported by a doctoral fellowship from CONICET. A.G.L. expresses her gratitude to Conservation, Research and Educational Opportunities (CREO) Organization for financial funding for a 2 mo training internship at the University of Swansea (Wales).

\section{LITERATURE CITED}

Arai N, Kuroki M, Sakamoto W, Naito Y (2000) Analysis of diving behaviour of Adélie penguins using acceleration data logger. Polar Biosci 13:95-100

Bearhop S, Thompson D, Waldron S, Russel IC, Alexander G, Furness R (1999) Stable isotopes indicate the extent of freshwater feeding by cormorants Phalacrocorax carbo shot at inland fisheries in England. J Appl Ecol 36:75-84

Bejder L, Samuels A, Whitehead H, Gales N and others (2006) Decline in relative abundance of bottlenose dolphins exposed to long-term disturbance. Conserv Biol 20: 1791-1798

Carss DN, Ekins GR (2002) Further European integration: mixed sub-species colonies of great cormorants Phalacrocorax carbo in Britain - colony establishment, diet, and implications for fisheries management. Ardea 90:23-41

> Cotton PA (2003) Avian migration phenology and global climate change. Proc Natl Acad Sci USA 100:12219-12222

> Davis RW, Fuiman LA, Williams TM, Collier SO and others (1999) Hunting behavior of a marine mammal beneath the Antarctic fast ice. Science 283:993-996

De Nie H (1995) Changes in the inland fish populations in Europe in relation to the increase of the cormorant Phalacrocorax carbo sinensi. Ardea 83:115-122

Gremillet D, Dell'Omo G, Ryan PG, Peters G, Ropert-Coudert Y, Weeks SJ (2004) Offshore diplomacy, or how seabirds mitigate intra-specific competition: a case study based on GPS tracking of Cape gannets from neighbouring colonies. Mar Ecol Prog Ser 268:265-279

Halsey LG, Shepard ELC, Hulston CJ, Venables MC, White CR, Jeukendrup AE, Wilson RP (2008) Acceleration versus heart rate for estimating energy expenditure and speed during locomotion in animals: tests with an easy model species, Homo sapiens. Zoology 1:231-241

> Johnson MP, Tyack PL (2003) A digital acoustic recording tag for measuring the response of wild marine mammals to sound. IEEE J Ocean Eng 28:3-12

McLellan BN, Shackleton DM (1988) Grizzly bears and resource extraction industries: effects of roads on behaviour, habitat use and demography. J Appl Ecol 25:451-460

Ropert-Coudert Y, Wilson RP (2005) Trends and perspectives in animal-attached remote sensing. Front Ecol Environ $3: 437-444$

Ropert-Coudert Y, Gremillet D, Kato A, Ryan PG, Naito Y, Le Maho Y (2004) A fine-scale time budget of Cape gannets provides insights into the foraging strategies of coastal seabirds. Anim Behav 67:985-992

Ryan HF, Petersen SL, Peters G, Grémillet D (2004) GPS tracking a marine predator: the effects of precision, resolution and sampling rate on foraging tracks of African penguins. Mar Biol 145:215-223

Sato K, Mitani Y, Cameron MF, Siniff DB, Naito Y (2003) Factors affecting stroking patterns and body angle in diving Weddell seals under natural conditions. J Exp Biol 206:1461-1470

> Shepard ELC, Wilson RP, Quintana F, Gómez Laich A and others (2008) Identification of animal movement patterns using tri-axial accelerometry. Endang Species Res 10: $47-60$

Simeone A, Wilson RP (2003) In-depth studies of Magellanic penguin (Spheniscus magellanicus) foraging: Can we estimate prey consumption by perturbations in the dive profile? Mar Biol 143:825-831

Tremblay Y, Cherel Y, Oremus M, Tveraa T, Chastel O (2003) Unconventional ventral attachment of time-depth recorders as a new method for investigating time budget and diving behaviour of seabirds. J Exp Biol 206:1929-1940

- Wallace MP (1994) Control of behavioral development in the context of reintroduction programs for birds. Zoo Biol 13:491-499

Watanabe S, Izawa M, Kato A, Ropert-Coudert Y, Naito Y (2005) A new technique for monitoring the detailed behaviour of terrestrial animals: a case study with the domestic cat. Appl Anim Behav Sci 94:117-131

> Watanuki Y, Niizuma Y, Gabrielsen GW, Sato K, Naito Y (2003) Stroke and glide of wing-propelled divers: Deep diving seabirds adjust surge frequency to buoyancy change with depth. Proc R Soc Lond B Biol Sci 270:483-488

> Watanuki Y, Takahashi A, Daunt F, Wanless S, Harris M, Sato K, Naito Y (2005) Regulation of stroke and glide in a footpropelled avian diver. J Exp Biol 208:2207-2216

- Weimerskirch H, Le Corre M, Jaquemet S, Marsac F (2005) Foraging strategy of a tropical seabird, the red footed booby, in a dynamic marine environment. Mar Ecol Prog Ser 288:251-261

Wilson RP, Putz K, Peters G, Culik B, Scolaro JA, Charrassin JB, Ropert-Coudert Y (1997) Long-term attachment of transmitting and recording devices to penguins and other seabirds. Wildl Soc Bull 25:101-106

Wilson RP, White CR, Quintana F, Halsey LG, Liebsh N, Martin GR, Butler PJ (2006) Moving towards acceleration for estimates of activity-specific metabolic rate in free-living animals: the case of the cormorant. J Anim Ecol 75:1081-1090

Wilson RP, Shepard ELC, Liebsch N (2008) Prying into intimate details of animal lives: use of a daily diary on animals. Endang Species Res 4:123-137

> Yoda K, Sato K, Niizuma Y, Kurita M, Bost C, Le Maho Y, Naito Y (1999) Precise monitoring of porpoising behaviour of Adelie penguins determined using acceleration data loggers. J Exp Biol 202:3121-3126

> Yoda K, Naito Y, Sato K, Takahashi A and others (2001) A new technique for monitoring the behaviour of free-ranging Adelie penguins. J Exp Biol 204:685-690

Submitted: November 4, 2007; Accepted: March 12, 2008

Proofs received from author(s): May 8, 2008 